\title{
DIVERGÊNCIA GENÉTICA DE ACESSOS DE MARACUJÁ UTILIZANDO DESCRITORES QUANTITATIVOS E QUALITATIVOS ${ }^{1}$
}

\author{
CRISTINA DE FÁTIMA MACHADO², FÁBIO NASCIMENTO DE JESUS ${ }^{3}$, \\ CARLOS ALBERTO DA SILVA LEDO ${ }^{4}$
}

RESUMO - Objetivou-se no trabalho caracterizar uma coleção de germoplasma de maracujá, com base em descritores quantitativos e qualitativos, e estimar a divergência com base na análise conjunta dos dados. Estudaram-se 22 acessos, procedentes da Coleção de maracujá da Embrapa Mandioca e Fruticultura. Foram utilizados 36 descritores morfoagronômicos, sendo 13 qualitativos e 23 quantitativos. Os dados foram analisados de forma conjunta pelo algoritmo de Gower. Adicionalmente, os acessos foram avaliados em condições de campo quanto à tolerância às doenças da parte aérea (antracnose, virose, bacteriose e verrugose) e das raízes (Fusarium). Houve variabilidade fenotípica entre os genótipos para as características morfoagronômicas estudadas, principalmente nos frutos, que mostraram diferenças acentuadas em teores de sólidos solúveis e vitamina C. O método aglomerativo utilizado foi UPGMA por ter maior coeficiente de correlação cofenética $\left(\mathrm{r}=0.94^{* *}\right)$. Os acessos estudados dividiram-se em três grupos. Foi possível identificar que dentro de um mesmo grupo existe similaridade entre os acessos. Contudo, entre os grupos, pode-se inferir sobre a presença de variabilidade para os descritores utilizados, incluindo aqueles de interesse agronômico. Verificou-se que existe variabilidade genética dentro das espécies silvestres ( $P$. suberosa e $P$. gibertii) e seu potencial de uso em programas de melhoramento genético, como fonte de vitamina $\mathrm{C}$ e como porta-enxertos (P. gibertii).

Termos para indexação: análise multivariada, diversidade, germoplasma, Passiflora.

\section{GENETIC DIVERGENCE OF THE ACESSIONS OF PASSION FRUIT USING QUANTITATIVE AND QUALITATIVE DESCRIPTORS}

\begin{abstract}
This study aims to characterize a collection of germplasm of Passiflora, based on quantitative and qualitative descriptors and use the Gower's algorithm to quantification of genetic divergence. We used 22 accessions, coming from the germplasm Collection of Embrapa Cassava and Fruits. We used 36 morphoagronomic descriptors, 13 qualitative and 23 quantitative. Data were analyzed by Grower's algorithm for the joint analysis. The accessions were evaluated under field conditions for tolerance to foliar diseases (anthracnose, viral, bacterial and scab) and roots (Fusarium). There was phenotypic variability among genotypes for morphological characteristics studied, mainly in fruits, which marked differences were observed in soluble solids and vitamin C contents of fruits. We used UPGMA to perform the clustering, since it was the method with the higher cophenetic correlation coefficient $(\mathrm{r}=0.94 * *)$. Accessions felt into three classes. It was possible to identify within a group there are some similarity among accessions. However, among groups, one can infer the presence of variability for the descriptors used, including those of agronomic interest. It has been found that there is variability within wild species (P. suberosa and P. gibertii) and its potential used in breeding programs as a source of vitamin $\mathrm{C}$ and as rootstocks ( $P$. gibertii)
\end{abstract}

Index terms: multivariate analysis, diversity, germplasm, Passiflora.

1(Trabalho 110-14). Recebido em: 28-03-2014. Aceito para publicação em: 18-09-2014.

${ }^{2}$ Dr. Pesquisador da Embrapa Mandioca e Fruticultura, Rua Embrapa, s/n, Caixa Postal 007, 44380-000 Cruz das Almas (BA). E-mail: cristina.fatima-machado@embrapa.br

${ }^{3}$ Estudante de doutorado da Universidade Federal do Recôncavo da Bahia, Avenida Alberto Passos, 294 - Centro, 44380-000. Cruz das Almas (BA). E-mail:fabiorock222@yahoo.com.br

${ }^{4}$ Dr. Pesquisador da Embrapa Mandioca e Fruticultura, Rua Embrapa, s/n, Caixa Postal 007, 44380-000 Cruz das Almas (BA). E-mail: carlos.ledo@embrapa.br 


\section{INTRODUÇ̃̃O}

O gênero Passiflora é o maior representante da família Passifloraceae, distribuída em aproximadamente 530 espécies e 400 híbridos artificiais (ULMER; MAC DOUGAL, 2004). Dentre estas 530 espécies, ao menos 140 são nativas do território brasileiro (CERVI, 2006), o que confere ao país a condição de um dos principais centros de diversidade genética do gênero. Esse gênero possui ampla variabilidade interespecífica e potencial para usos diversos, tanto alimentar, medicinal, quanto ornamental, ainda subutilizados.

Apesar da ampla diversidade genética dentro do gênero Passiflora, em função do elevado número de espécies, as pesquisas com maracujazeiro estão sendo amplamente dirigidas às espécies cultivadas, principalmente a $P$. edulis, no entanto sabe-se que algumas espécies, não cultivadas, podem contribuir substancialmente para o melhoramento genético, por apresentarem resistência a doenças ou a pragas, longevidade, maior adaptação a condições climáticas adversas, período de florescimento ampliado, maior concentração de componentes químicos interessantes para a indústria farmacêutica e outras potencialidades, quase todas ainda inexploradas (MELETTI, 2011) ou com ações de pesquisa e desenvolvimento ainda incipientes (FALEIRO et al., 2011). A manutenção e a conservação desta variabilidade em bancos de germoplasma são de fundamental importância para o melhoramento genético, pela possibilidade de identificação de genes que podem conferir melhores características de produção, qualidades organolépticas e de adaptação a diferentes estresses abióticos e bióticos (GEPTS, 2006; GONÇALVES et al., 2008; FALEIRO et al., 2011).

O uso de técnicas multivariadas é um dos fatores que têm impulsionado o aumento nos estudos sobre divergência genética entre acessos de banco de germoplasma. Entre as técnicas mais utilizadas destacam-se a análise por componentes principais, por variáveis canônicas, e os métodos aglomerativos (MOHAMMADI; PRASANNA, 2003). O método aglomerativo tem como princípio reunir os genótipos em grupos, de tal forma que haja homogeneidade dentro destes e heterogeneidade entre os mesmos. Esta metodologia depende do cálculo das medidas de dissimilaridade provenientes de variáveis quantitativas e/ ou qualitativas (CROSSA; FRANCO, 2004).

A técnica que permite a análise simultânea de dados quantitativos e qualitativos foi proposta por Gower (1971). Este método permite a análise simultânea de variáveis contínuas e categóricas, utilizando uma escala de 0 a 1 , independentemente do número de variáveis, como uma base de dados para a padronização (CROSSA; FRANCO, 2004), o que facilita a construção de um dendrograma (MASON et al., 2005).

Os objetivos do presente trabalho foram: caracterizar acessos de maracujá, pertencentes à coleção da Embrapa - CNPMF, com base em descritores qualitativos e quantitativos, e estimar a divergência com base na análise conjunta dos dados quantitativos e qualitativos.

\section{MATERIAL E MÉTODOS}

O experimento foi conduzido em área experimental e no Laboratório de Pós-Colheita da Embrapa Mandioca e Fruticultura (CNPMF), no município de Cruz das Almas (BA), no período de agosto de 2011 a agosto de 2012. O município está situado a $12^{\circ} 40^{\prime \prime} 19^{\text {"'t" }}$ de latitude sul e $39^{\circ} 06^{\prime \prime} 22^{\prime \prime \prime \prime}$ de longitude oeste, a $220 \mathrm{~m}$ acima do nível do mar. O clima é tropical quente e úmido, Aw a Am, segundo a classificação de Köppen, com temperatura média anual de $24,5^{\circ} \mathrm{C}$, umidade relativa de $80 \%$ e precipitação média de $1.249,7 \mathrm{~mm}$ anuais (AGRITEMPO, 2014).

Foram caracterizados, utilizando descritores morfoagronômicos, 22 acessos de maracujá, procedentes da Coleção de Germoplasma da Embrapa - CNPMF (Passiflora cincinnata Mast (BGP 358, BGP 375, BGP 363, BGP 362a, BGP 364 e BGP 362b); P. edulis Sims 'amarelo'. (BGP 360a, BGP 373, BGP 361, BGP 371a, BGP 371b, BGP 371c, BGP 331 e BGP 382); P. edulis Sims 'roxo' (BGP 374 e BGP 360b); P. gibertii NE Brown (BGP 008); P. mucronata Lam (BGP 114); P. setacea DC. (BGP 357); P. morifolia Mast (BGP 107); P. suberosa Linnaeus (BGP 014) e P. alata Curtis (BGP 004). No presente estudo, cada acesso foi representado por duas plantas na parcela, espaçadas de 2,5 $\mathrm{m}$ x 5,0 m, no sistema de espaldeira, com um fio de arame situado a $1,80 \mathrm{~m}$ do nível do solo. Foram utilizados 36 descritores morfoagronômicos, sendo 13 descritores qualitativos $(3$ relacionados às folhas, 8 relacionados às flores e 2 relacionados aos frutos), 23 descritores quantitativos (3 relacionados às folhas, 8 relacionados às flores e 12 relacionados aos frutos). Os acessos foram avaliados também em condições naturais quanto à tolerância relativas às doenças da parte aérea (antracnose, virose, bacteriose e verrugose) e do solo (Fusarium).

Os descritores de folha foram determinados pela coleta em uma planta de cada acesso, em que cada planta foi dividida em quatro quadrantes (norte, 
sul, leste e oeste). De cada quadrante, foi escolhido um ramo localizado na altura mediana da planta, de onde foram removidas 3 folhas, totalizando 12 folhas de cada acesso, sendo que dessas, apenas, 10 foram utilizadas no estudo.

$\mathrm{Na}$ determinação dos descritores de flor, foi escolhida em cada acesso, aleatoriamente, uma planta e 10 flores por acesso, e um total de 220 flores analisadas.

Trinta frutos do acesso de $P$. suberosa, três dos acessos de $P$. mucronata e $P$. gibertii, cinco do acesso de $P$. morifolia e um dos acessos de $P$. alata, P. cincinnata, $P$. edulis, $P$. setacea, foram utilizados para compor a amostra na caracterização física $\mathrm{e}$ química. Vinte análises químicas foram realizadas, em amostras de frutos de cada acesso, exceto vitamina $\mathrm{C}$, sendo realizadas quatro análises, em amostras de frutos de cada acesso. Para os descritores físicos, foram analisados 20 frutos de cada acesso. Os frutos foram colhidos no período de abril a agosto de 2012, quando os mesmos apresentavam sinais de amaciamento.

O estudo biométrico dos frutos foi realizado no Laboratório de Pós-Colheita da Embrapa Mandioca e Fruticultura - CNPMF, sendo mensuradas as seguintes características: diâmetro longitudinal do fruto $(\mathrm{mm})$; diâmetro transversal do fruto $(\mathrm{mm})$; massa média de frutos (gramas); massa da casca + semente (gramas); rendimento da polpa - expresso em porcentagem; espessura da casca ( $\mathrm{mm}$ ); teor de sólidos solúveis (SS - em grau Brix); acidez titulável ( $\mathrm{AT}$ = grama de ácido cítrico por $100 \mathrm{~mL}$ de suco), relação SS/AT; vitamina C.

Na determinação dos descritores da produção, foram mensuradas as seguintes características: número total de frutos por planta e massa total de frutos (kg planta ${ }^{-1}$ ), ano de produção: 2011/2012.

Nas determinações métricas, utilizou-se de paquímetro digital ( $200 \mathrm{~mm} / 8$ " $-0,01 \mathrm{~mm} / .0005 ")$, e as massas foram obtidas com auxílio de balança analítica. O teor de sólidos solúveis foi determinado por refratometria, utilizando-se de um refratômetro portátil, com leitura na faixa de 0 a $32^{\circ}$ Brix. A acidez titulável (AT) foi expressa em gramas de ácido cítrico por $100 \mathrm{~mL}$ de suco. O teor de vitamina $\mathrm{C}$ ( $\mathrm{mg}$ de ácido ascórbico $/ 100 \mathrm{~g}^{-1}$ ) foi realizado pelo método do espectrofotômetro.

Inicialmente, realizou-se análise individual para as variáveis quantitativas e qualitativas, utilizando a distância euclidiana média e a distância de Cole-Rodgers (COLE-RODGERS et al., 1997), respectivamente. Uma análise conjunta dos dados qualitativos e quantitativos foi realizada para a determinação da distância genética, com base no algoritmo de Gower (1971).

Os agrupamentos hierárquicos das análises individuais e simultâneas a partir das matrizes de distância genética foram obtidos pelo método de UPGMA - Unweighted Pair Group Method with Arithmetic Mean. A validação dos agrupamentos foi determinada pelo coeficiente de correlação cofenético (CCC) (SOKAL; ROHLF, 1962). A significância dos CCC foi calculada pelo teste $t$ de Mantel, com 1.000 permutações (MANTEl, 1967).

Para a obtenção das matrizes de distância genética das análises individuais e cálculo dos CCC (coeficiente de correlação cofenética), foi utilizado o programa Genes (CRUZ, 2008). A matriz de distância genética utilizando o algoritmo de Gower foi obtida pelo programa R (R Development Core Team, 2014). O dendrograma foi obtido pelo programa Statistica 7.1 (STATSOFT, 2005). O critério utilizado para a definição do número de grupos ideal foi o pseudo- $\mathrm{t}^{2}$, calculado com auxílio do pacote "NbClust" do programa R (CHARRAD et al., 2014)

\section{RESULTADOS E DISCUSSÃO}

As análises individuais das variáveis quantitativas e qualitativas apresentaram valores de coeficiente de correlação cofenético entre a matriz de distância e a de agrupamento de $0,91^{* *}$ e $0,93^{* *}$, respectivamente (Tabela 1 ). Já a análise simultânea das variáveis quantitativas e qualitativas pelo algoritmo de Gower apresentou o maior coeficiente de correlação cofenético, com o valor de $0,94 * *$. Utilizando o critério do pseudo- $\mathrm{t}^{2}$ foi possível observar a formação de 2; 2 e 3 grupos, respectivamente, para as análises baseadas nos dados quantitativos, qualitativos e conjunta.

Observa-se que a matriz de distância conjunta apresentou valores de correlações altos e significativos com as matrizes de distância obtidas nas análises individuais, de $0,81^{* *}$ e $0,85^{* *}$, para as variáveis quantitativas e qualitativas, respectivamente (Tabela 1). A correlação entre as análises individuais apresentou valor baixo e significativo de $0,45^{* *}$, o que implica fraca associação entre essas variáveis.

De acordo com os valores de matriz de dissimilaridade, a maior distância entre os acessos foi de 0,84, entre BGP 014 (P. suberosa) e BGP 004 (P. alata). Do ponto de vista agronômico, ambas as espécies são interessantes, pois são consideradas resistentes à morte precoce e a outras doenças causadas por patógenos do solo; além disso, no Brasil, a $P$. alata (maracujá-doce) é considerada a 
segunda espécie com maior expressão econômica.

O agrupamento hierárquico UPGMA(Figura 1) apresentou valor para a correlação cofenética ( $\mathrm{r}$ $=0,94 * *)$ altamente significativo. Segundo Sokal e Rohlf (1962), valores de correlação iguais ou acima de 0,80 são considerados bons quando correlacionam a matriz de distância e a matriz de agrupamento, e, ainda, quanto maior este valor, maior é a eficiência do método em questão.

A análise simultânea pelo algoritmo de Gower foi utilizada para representar graficamente a variabilidade dos genótipos de maracujazeiro pela sua maior eficiência em quantificar as diferenças entre eles (Figura 1). Pelo critério do pseudo- $\mathrm{t}^{2}$, podese observar que o ponto de máximo foi atingido no passo da formação de três grupos, indicando que este ponto está relacionado com a menor probabilidade de significância do teste e, consequentemente, indica a interrupção do processo de agrupamento. Sendo assim, três grupos foram determinados como ideais para a análise do agrupamento UPGMA (Figura 1), a saber:

O grupo I foi constituído pelo maior número de acessos, totalizando 19 genótipos, pertencentes a diferentes espécies. Este grupo pode ser dividido em 4 subgrupos: o primeiro com 6 acessos de $P$. cincinnata; o segundo com 8 acessos de $P$. edulis Sims 'amarelo' e 2 acessos de P. edulis Sims 'roxo'; o terceiro com apenas 1 acesso de $P$. gibertii (BGP 008); o quarto com 2 acessos, P. setacea (BGP 357) e $P$. mucronata (BGP 114). Este grupo revelou alta variabilidade para a maioria das características avaliadas, como pode ser observado na Figura 1.

As espécies do grupo I destacaram-se com relação aos descritores de frutos e apresentaram médias expressivas de sólidos solúveis (SS) - (BGP 008 - 19,03 ${ }^{\circ}$ Brix, BGP $114-16,45^{\circ}$ Brix e BGP 357 - 16,45 ${ }^{\circ}$ Brix) e Ratio (SS/AT) - (BGP 008 - 53,76, BGP 114-11, 27 e BGP 357 - 8,08). Para a indústria de sucos de maracujá, o teor de sólidos solúveis de 11,4 a 15,3 , acidez titulável de 2,7 a 3,9 g de ácido cítrico $100 \mathrm{~mL}^{-1}$ e relação Brix/acidez de 3,5 a 4,7 conferem maior palatabilidade (NAGATO et al., 2003).

Flores et al.(2011), em estudo de caracterização físico-química de frutos de maracujazeiro P. edulis, observaram que os sólidos solúveis e ratio variaram de 13,1 a $15,5^{\circ}$ Brix e 3,2 a 4,1, respectivamente; portanto, valores inferiores aos encontrados nas espécies que formaram o grupo I. Houve divergência entre as espécies do grupo I, com relação à vitamina C - (BGP 008 - apresentou valor de 79,90 mg de ácido ascórbico/100 g, BGP 114 - 41,94 mg de ácido ascórbico/100 g e BGP 357 - 24,38 mg de ácido ascórbico/100 g).

O grupo II foi formado pelos acessos $P$. morifolia (BGP 107) e P. suberosa (BGP 014), e os genótipos dessse grupo apresentaram características agronômicas contrastantes e de interesse sob o ponto de vista agronômico e funcional; por exemplo, a $P$. suberosa apresentou alto contéudo de vitamina $\mathrm{C}$, tolerância à Murcha de Fusarium e à verrugose; já a $P$. morifolia apresentou conteúdo de vitamina $\mathrm{C}$ inferior à primeira espécie e tolerância à bacteriose, fusariose, verrugose e virose; por outro lado, os frutos de ambos os genótipos têm coloração de casca roxa.

Em relação ao grupo III, constituído apenas pelo acesso BGP 004 (P. alata), o genótipo apresentou tolerância à Murcha de Fusarium, alto conteúdo de sólidos solúveis em sua polpa e, ainda, a espécie apresenta interesse comercial; portanto, é de grande relevância seu uso em programa de melhoramento.

Observaram-se os seguintes descritores com os maiores valores médios entre as espécies analisadas: largura de folhas ( $P$. cincinnata $-10,97$ cm; P. edulis 'amarelo'- 17,71 cm e $P$. edulis 'roxo' - 13,4 cm) e comprimento de pecíolo $(P$. cincinnata $-4,13 \mathrm{~cm} ; P$. edulis 'amarelo' - 3,94 cm e $P$. edulis 'roxo' $-3,23 \mathrm{~cm})$. No que tange à massa de fruto, $P$. cincinnata, obteve-se um valor médio de $88,18 \mathrm{~g}$, enquanto $P$. edulis 'amarelo' e $P$. edulis 'roxo' apresentaram médias de 136,8 e 145,6 $\mathrm{g}$, respectivamente. Esses resultados concordam em parte com os obtidos por Flores et al. (2011), que observaram, que a massa dos frutos variou de 102,5 a 202,06 g. Os acessos do grupo em questão também se destacaram em relação à acidez titulável (AT), (P. cincinnata - 4,23\%; P. edulis 'amarelo'-3,66 $\%$ e $P$. edulis 'roxo' $-3,20 \%$ de ácido cítrico em $100 \mathrm{~mL}$ de suco). A acidez constitui uma variável de grande interesse para o estado de conservação de produtos alimentícios. De acordo com Pinto et al. (2003), pode-se considerar que os genótipos com acidez titulável acima de 1,00\% em ácido cítrico são os de maior interesse para a agroindústria, tendo em vista não haver necessidade da adição de ácido cítrico para a conservação da polpa, que é um artifício utilizado para dificultar o desenvolvimento de microrganismos. Além disso, observaram-se os maiores rendimentos de polpa (P. cincinnata - 35,39 $\%$; P. edulis 'amarelo'- 34,18 \% e P. edulis 'roxo' $26,95 \%$ ) e também os maiores valores médios para a produção ( $P$. cincinnata $-11,52 \mathrm{~kg} \mathrm{planta}^{-1} ; P$. edulis 'amarelo'- 14,12 kg planta ${ }^{-1}$ e P. edulis 'roxo' - 12,83 kg planta $\left.^{-1}\right)$.

Os descritores mais divergentes entre os acessos BGP 014 e BGP 004 foram os sólidos solúveis 
(SS) e o teor de vitamina C (VITC). Verificou-se que o acesso BGP 014 apresentou o teor médio de vitamina $\mathrm{C}$ de $165,04 \mathrm{mg}$ de ácido ascórbico $100 \mathrm{~g}^{-1}$ de polpa, enquanto o acesso BGP 004 apresentou a média de 12,2 mg de ácido ascórbico/100 g-1 . Quanto aos sólidos solúveis, o acesso BGP 004 apresentou a média de $14,6^{\circ}$ Brix, enquanto o genótipo BGP 014 apresentou a média de $3,96^{\circ} \mathrm{Brix}$. Os acessos mais próximos foram BGP 360 ( $P$. edulis 'roxo') e BGP 361 (P. edulis 'amarelo') com distância de 0,28. Flores et al. (2011) observaram que os valores de vitamina $\mathrm{C}$ ultrapassaram o valor de $20 \mathrm{mg}$ de ácido ascórbico $100 \mathrm{~g}^{-1}$ de polpa que, segundo Santos et al. (2009), é normalmente observado em frutos de maracujazeiro-amarelo.

Outro aspecto a ser considerado é que a maioria das características estudadas no presente trabalho é do tipo quantitativo, no total de 36 contra apenas 13 características qualitativas. Dentre as variáveis quantitativas estudadas, estão as mais amplamente utilizadas na caracterização agronômica, que são peso médio de frutos, número de frutos por planta, comprimento e diâmetros de frutos. Por outro lado, dentre as variáveis qualitativas estudadas, estão as mais utilizadas na caracterização morfológica. É importante ressaltar que cada conjunto de dados, seja quantitativo, seja qualitativo, tem suas vantagens e desvantagens para análise (MOHAMMADI; PRASANNA, 2003), e muitos dados têm sido gerados, demonstrando a importância de se conhecer esses descritores (LOTTI et al., 2008).

Ainda, com a análise conjunta dos dados, foi possível alocar os acessos em um único dedrograma, utilizando-se de diferentes tipos de variáveis. Isso permitiu melhor análise e uso dos dados qualitativos que, em geral, são analisados apenas por estatística descritiva.

A distância proposta por Gower foi também utilizada por Rodríguez et al. (2005) para estudar, em conjunto, variáveis qualitativas e quantitativas, oriundas de 28 caracteres morfológicos e agronômicos em Brassica napus L. Com o estudo, os autores determinaram a adequação do germoplasma estudado para o cultivo de verão e estimaram a divergência genética entre as populações locais. Com a análise conjunta dos dados, os autores conseguiram demonstrar a diversidade e o valor dos acessos estudados para o melhoramento da cultura. Outros autores usaram a metodologia e observaram resultados promissores: Capsicum chinense Jacquin (MOURA et al., 2010); Papaya sp. L. (NETO et al., 2010); Pineapple sp. L. (Merr) (MACHADO et al., 2011).

Com relação às avaliações das principais doenças que surgiram na coleção, em condições naturais, verificou-se que a maioria das espécies que fazem parte do grupo I apresentou suscetibilidade ao Fusarium oxysporum f. sp. passiflorae, exceto $P$. gibertii, $P$. setacea e $P$. mucronata, enquanto as espécies integrantes dos grupos II e III não apresentaram sintomas característicos de fusariose. Portanto, os genótipos que apresentaram tolerância à Murcha de Fusarium poderão ser testados como porta-enxertos para o maracujá-amarelo. Além disso, a antracnose foi a doença que mais se proliferou, estando presente em $100 \%$ dos acessos das espécies avaliadas. Segundo Almeida e Coelho (2006), a antracnose, causada por Colletotrichum gloeosporioides (Penz.) Penz. \& Sacc., é a doença mais importante do maracujá-amarelo, P. edulis, na pós-colheita, sendo que a ocorrência da doença provoca danos graves nos frutos.

As viroses também apresentaram grande proliferação entre as espécies avaliadas, sendo a menor incidência observada na espécie $P$. suberosa (BGP 014), onde apenas $20 \%$ das plantas apresentaram sintomas. O maracujazeiro-amarelo pode ser infectado por diferentes vírus, sendo que, no Brasil, o vírus do endurecimento dos frutos - PWV (Passion fruit woodness virus), é considerado o mais importante. O PWV causa danos quantitativos e qualitativos à produção, reduzindo número, peso e valor comercial dos frutos.

Foi possível observar, também, a presença de sintomas característicos da bacteriose, causada por Xanthomonas campestris pv. Passiflorae, e verrugose, causada por Cladosporium cladosporioides em genótipos avaliados, exceto para $P$. gibertii, P. mucronata (Grupo I) e $P$. morifolia (grupo II).

Com relação à verrugose, não houve identificação da doença nas espécies $P$. gibertii, $P$. setacea e $P$. mucronata (grupo I), $P$. morifolia e $P$. suberosa (grupos II).

No caso específico de maracujazeiro das espécies $P$. gibertii e $P$. suberosa, os resultados deste estudo permitiram constatar a ampla variabilidade genética existente dentro das espécies silvestres e seu potencial de uso em programas de melhoramento genético, como fonte de vitamina $\mathrm{C}$ e como portaenxertos (P. gibertii). 
TABELA 1- Correlação entre matrizes de distância genética, coeficiente de correlação cofenético (CCC) estimado para os dados das variáveis quantitativas, qualitativas, análise simultânea em 22 genótipos de maracujá e número de grupos formados (NGF). Cruz das Almas-Bahia, 2013.

\begin{tabular}{lccccc}
\hline Matriz de distância & Quantitativa & Qualitativa & Conjunta & CCC & NGF \\
\hline Quantitativa & 1,00 & & $0,91 * *$ & $2^{1}$ \\
Qualitativa & $0,45^{* *}$ & 1,00 & & $0,93 * *$ & 2 \\
Conjunta & $0,81^{* *}$ & $0,85^{* *}$ & 1,00 & $0,94 * *$ & 3 \\
\hline
\end{tabular}

** Significativo a $1 \%$ pelo teste de Mantel, com 1.000 permutações. ${ }^{1}$ Baseado no critério do pseudo- $\mathrm{t}^{2}$.

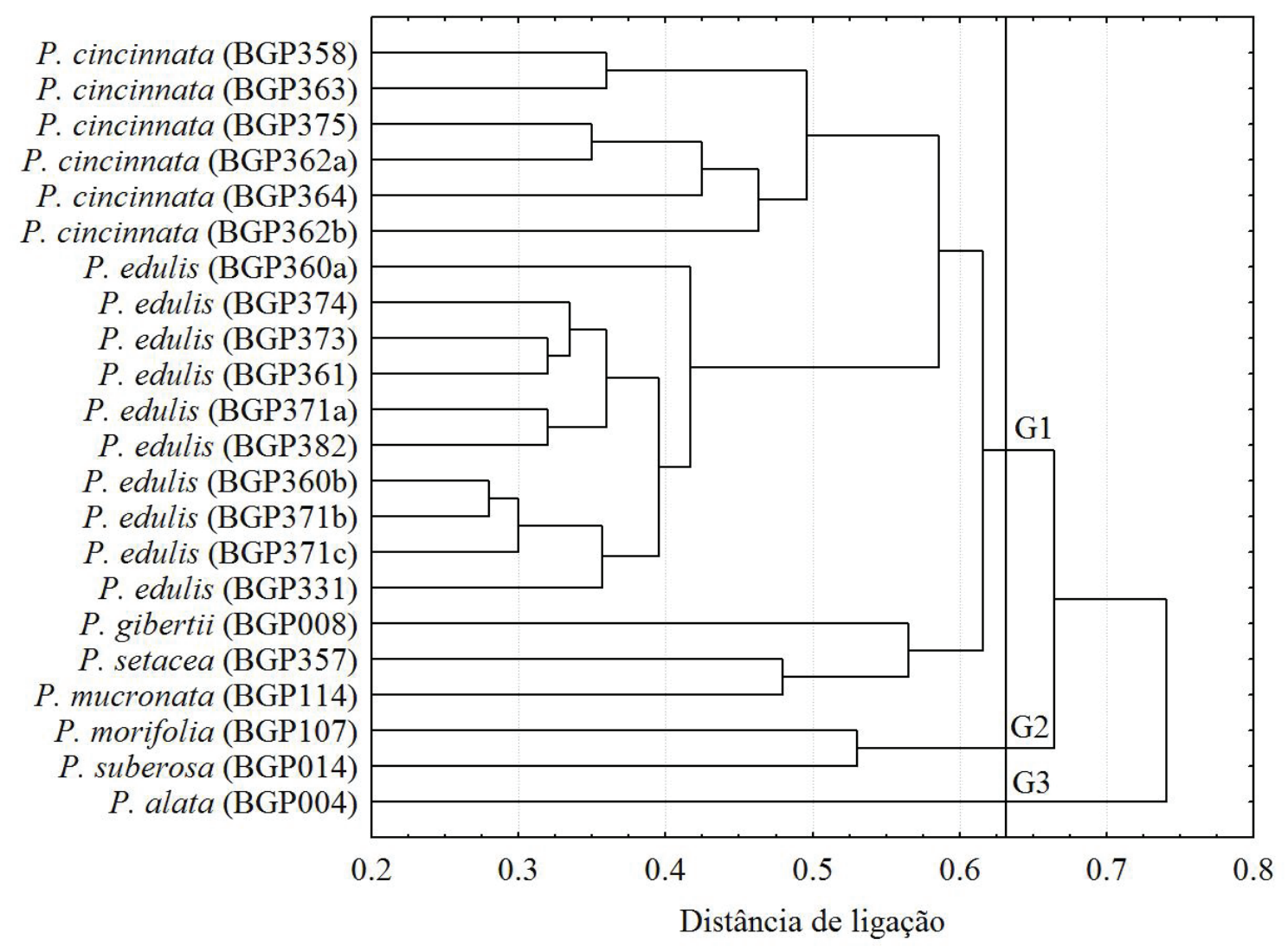

FIGURA 1- Dendrograma de dissimilaridade genética entre 22 genótipos de maracujá, obtido pelo método UPGMA, com base no algoritmo de Gower, a partir de 13 caracteres qualitativos e 23 quantitativos. 


\section{CONCLUSÕES}

A utilização de descritores morfoagronômicos evidenciou a existência de variabilidade genética entre os acessos da coleção de maracujá da Embrapa Mandioca e Fruticultura, sobretudo em relação aos componentes físicos (massa total do fruto, comprimento e largura de fruto), químicos (sólidos solúveis e vitamina $\mathrm{C}$ ), produção (kg de fruto por planta) e em relação às doenças do solo (fusariose) e da parte aérea (bacteriose e verrugose).

Alguns dos acessos presentes na coleção de maracujá mostraram-se promissores, indicando que os mesmos podem ser utilizados em programas de melhoramento para obtenção de híbridos interespecíficos entre espécies silvestres e variedades de maracujazeiro.

A análise conjunta de dados qualitativos e quantitativos é viável e pode permitir maior eficiência no conhecimento da divergência entre acessos de bancos de germoplasma.

\section{REFERÊNCIAS}

AGRITEMPO. Disponível em: http://www. agritempo.gov.br/agroclima/pesquisaweb? uf=ba. Acesso em: 17 fev. 2014.

ALMEIDA, L.C.C. de; COELHO, R.S.B. Efeito de indutores químicos no controle da antracnose do maracujá-amarelo pós-colheita. Fitopatologia Brasileira, Brasília, v. 31, p. 318-319, 2006.

CERVI, A.C. O gênero Passiflora L. (Passifloraceae) no Brasil, espécies descritas após o ano de 1950. Adumbrationes ad Summae Editionem, Madrid, v. 16, p.1-5, 2006.

CHARRAD, N; GHAZZALI N; BOITEAU, V; NIKNAFS, A. NbClust: NbClust package for determining the best number of clusters. R package version 2.0.1. Disponível em: http://CRAN.Rproject.org/package=NbClust. 2014. Acesso em 14 . jan. 2014.

COLE-RODGERS, P; SMITH D.W; BOSLAND, P.W. A novel statistical approach to analyze genetic resource evaluations using Capsicum as an example. Crop Science, Madison, v.37, p. 1, 1997.
CROSSA, J; FRANCO, J. Statistical methods for classifying genotypes. Euphytica, Dordrecht, v. 137, p. 19-37, 2004.

CRUZ, C.D . Programa genes: diversidade genética. Viçosa: Editora UFV, 2008. v. 1, 278 p.

FALEIRO, F.G; JUNQUEIRA, N.T.V; BRAGA, M.F; PEIXOTO, J.R. Pré-melhoramento do maracujá. In: LOPES, M.A; FAVERO, A.P; FERREIRA, M.A.J.F; FALEIRO, G; FOLLE, S.M. (Ed.). Pré-melhoramento de plantas: estado da arte e experiências de sucesso. Brasília: Embrapa Informação Tecnológica, 2011. p. 550-569.

FLORES, P.S; SILVA, D.F.P da; BRUCKNER, C.H; OLIVEIRA, S.P de; SALOMÃO, L.C.C. Caracterização físico-química de frutos de maracujazeiro provenientes da irradiação com raios gama. Ciéncia Rural, Santa Maria, v.41, n.11, 2011.

GEPTS, P. Plant genetic resources conservation and utilization: the accomplishments and future of a societal insurance policy. Crop Science, Madison, v. 46, n. 5, p. 2278-2296, 2006.

GONÇALVES, L.S.A; RODRIGUES, R; SUDRÉ, C.P; BENTO, C.dos; MOULIN, M.M; ARAÚJO, M.L.de; DAHER, R.F; PEREIRA, T.N.S; PEREIRA, M.G. Divergência genética em tomate estimada por marcadores RAPD em comparação com descritores multicategóricos. Horticultura Brasileira, Brasília, v. 26, n. 3, p. 362-368. 2008.

GOWER, J.C. A general coefficient of similarity and some of its properties. Biometrics, Arlington, v. 27, n. 4 , p. $857-874.1971$.

LOTTI C; MARCOTRIGIANO A.R; GIOVANNI C; RESTA P; RICCIARDI A; ZONNO V; FANIZZA G; RICCIARD L. Univariate and multivariate analysis performed on bio-agronomical traits of Cucumis melo L. germplasm. Genetic Resources and Crop Evolution, Dordrecht, v. 55, p. 511-522, 2008.

MACHADO, C. de F; SOUZA, F.V.D; LEDO, C.A.da S; CABRAL, J.R.S. Cluster analysis using quantitative, qualitative and molecular traits for the study of the genetic diversity in pineapple genotypes. Acta Horticulturae, The Hague, v. 902, p. 159-162, 2011. 
MANTEL, N. The detection of disease clustering and generalized regression approach. 161 Cancer Research, Birmingham, v.27, p.209-220, 1967.

MASON, N.W.H; MOUILLOT, D; LEE, W.G; WILSON, J.B. Functional richness, functional evenness and functional divergence: the primary components of functional diversity. Oikos, Rio de Janeiro, v.111, p.112-118, 2005.

MELETTI, L.M.M. Avanços na cultura do maracujá no Brasil. Revista Brasileira de Fruticultura, Jaboticabal, p.83-091, 2011. Volume Especial.

MOHAMMADI, A.S; PRASANNA, B.M. Analysis of genetic diversity in crop plants - salient statistical tools and considerations. Crop Science, Madison, v. 43, p. 1235-1248, 2003.

MOURA, M.C.C.L; GONÇALVES, L.S.A; SUDRÉ, C.P; RODRIGUES, R; AMARAL JÚNIOR, T.A; PEREIRA, T.N.S. Algoritmo de gower na estimativa de divergência genética em germoplasma de pimenta. Horticultura Brasileira, Brasília, v.28, p. 155-161, 2010.

NAGATO, L.A.F; RODAS, M.A. de. B; CANO, C.B; BARSOTTI, R.C.F; YOTSUYANAGI, K. parâmetros físicos e químicos e aceitabilidade sensorial de sucos de frutas integrais, maracujá e uva, de diferentes marcas comerciais brasileiras. Brazilian Journal of Food Technology, Campinas, v.1, n.6, p. 127-136, 2003.

NETO, F.V.B; LEAL, N.R.; GONÇALVES, L.S.A; FILHO, L.M.R; JÚNIOR, A.T.A. Descritores quantitativos na estimativa da diversidade genética entre genótipos de mamoeiro utilizando análises multivariadas. Ciência Agronômica, Fortaleza, v.41, p. 294-299, 2010.
PINTO, W.S; DANTAS, A.C.V.L; FONSECA, A.A.O; LEDO, C.Ada S; JESUS, S.C; CALAFANGE, P.L.P; ANDRADE, E.M. Caracterização física, físico-química e química de frutos de genótipos de cajazeiras. Pesquisa Agropecuária Brasileira, Brasília, v. 38, n. 9, p. 1059-1066, 2003.

$\mathrm{R}$ Development Core Team. A language and environment for statistical computing. Vienna: R Foundation for Statistical Computing; 2014. Disponível em: <http://www.R-project.org/>. Acesso em: 14. jan. 2014.

RODRÍGUEZ, V.M.; CARTEA, M.E; PADILLA, G; VELASCO, P; ORDAS, A. The nabicol: A horticultural crop in northwestern Spain. Euphytica, Dordrecht, v. 142, n.3, p.237-246, 2005.

SANTOS, C.E.M. dos; BRUCKNER, C.H; CRUZ, C.D; SIQUEIRA, D.L de; PIMENTEL, L.D. Características físicas do maracujá-azedo em função do genótipo e massa do fruto. Revista Brasileira de Fruticultura, Jaboticabal, v. 31, n. 4, p.1102-1110, 2009.

SOKAL, R.R; ROHLF, F.J. The comparison of dendrograms by objective methods. Táxon, Utrecht, v.11, p. 33-40, 1962.

STATSOFT. Statistica for windows (data analysis software system), version 7.1. Tulsa, 2005.

ULMER, T; MAC DOUGAL, J.M. Passiflora: passion flowers of the world. Portland Oregon: Timber Press, 2004. p. 430. 